\title{
Bromination of Pd Compounds during Thermal Decomposition of Tetrabromobisphenol A
}

\author{
Shunsuke Kuzuhara1, Ayaka Sano ${ }^{1,2}$ \\ ${ }^{1}$ National Institute of Technology, Sendai College, Miyagi, Japan \\ ${ }^{2}$ Senju Metal Industry Co., Ltd, Tokyo, Japan \\ Email: kuzuhara@sendai-nct.ac.jp
}

How to cite this paper: Kuzuhara, S. and Sano, A. (2018) Bromination of Pd Compounds during Thermal Decomposition of Tetrabromobisphenol A. Engineering, 10, 187-201.

https://doi.org/10.4236/eng.2018.104013

Received: March 23, 2018

Accepted: April 27, 2018

Published: April 30, 2018

Copyright (C) 2018 by authors and Scientific Research Publishing Inc. This work is licensed under the Creative Commons Attribution International License (CC BY 4.0).

http://creativecommons.org/licenses/by/4.0/

\section{(c) (i) Open Access}

\begin{abstract}
We conducted thermal tests using the reagent tetrabromobisphenol $\mathrm{A}$ (TBBPA) and various Pd compounds to study the chemical forms of Pd obtained during the pyrolytic and oxidative decomposition of TBBPA. Thermal testing was conducted in an electric furnace at temperatures of $280^{\circ} \mathrm{C}-800^{\circ} \mathrm{C}$ in an $\mathrm{Ar}$ or $\mathrm{Ar}-\mathrm{O}_{2}(5 \%)$ atmosphere for a heating period of $40 \mathrm{~min}$. Scanning electron microscopy-energy dispersive $\mathrm{X}$-ray spectroscopy results revealed that Pd bromide was formed in the mixture of TBBPA and PdO after heating to $450^{\circ} \mathrm{C}$ in the $\mathrm{Ar}$ atmosphere. In addition, thermogravimetry-differential thermal analysis showed that as the heating temperature was increased from $350^{\circ} \mathrm{C}$ to $730^{\circ} \mathrm{C}$, weight loss occurred at a nearly constant rate, indicating that $\mathrm{Pd}$ bromide decomposed in this temperature range.
\end{abstract}

\section{Keywords}

Tetrabromobisphenol A, Palladium, Waste Electrical and Electronic Equipment, Bromination, Thermal Processes

\section{Introduction}

Small electronic devices including mobile phones, laptop, digital cameras, and game consoles are essential in our daily lives, and the demand for these products is projected to increase. The increasing demand for small electronics will also lead to an increase in the generation of waste electrical and electronic equipment (WEEE). Approximately 4500 tonnes of WEEE is produced annually [1], and this quantity is projected to increase as developing countries grow.

Circuit boards in WEEE are highly valuable, since they contain metals including $\mathrm{Cu}, \mathrm{Ag}, \mathrm{Au}$, and Pd [2] [3] [4]. Several metal recovery methods have been proposed, including pyrometallurgy [5], hydrometallurgy [6] [7] [8], bio- 
technology [4] [9], and supercritical [10] [11] and high-voltage electrical pulse methods [12]. In particular, pyrometallurgy has been commercialised because of its potential for processing large volumes of materials [5]. From the perspective of metal quality, waste circuit boards rank higher than ores [13] and are suitable for recycling. However, they also contain flame retardants, which not only damage the equipment because of the halogens present within but also adversely affect metal recovery rates. Commonly used flame retardants include high impact polystyrene, acrylonitrile-butadiene-styrene, and tetrabromobisphenol A (TBBPA), with TBBPA being the most widely used.

The principal decomposition component in the thermolysis and pyrolysis of TBBPA is $\mathrm{HBr}$ [8] [14]; however, many organic compounds such as phenols and bromophenols are also formed [14]-[20]. The formation pathways [21] of polybrominated dibenzo-p-dioxins and dibenzofurans are still being studied.

Halogens are considered as aversive substances in metal recovery processes, with chloride volatilisation as an example of its positive use. By exploiting the chlorination reaction of metals [22] [23] [24], metal recovery can be in an energy-efficient manner; similarly, the bromination reaction of metals [25] can also be used. Basic information regarding the bromination reaction of metals is needed to increase the rate of metal recovery from waste circuit boards and prevent unintentional loss, and studies have been conducted using thermodynamic calculations [26]. Experimental quantitative analysis regarding the bromination behaviour of $\mathrm{Zn}$ has been conducted through thermal testing of samples containing $\mathrm{ZnO}$ and TBBPA [27] [28] [29]. Similar studies have been conducted for many other metals including $\mathrm{PbO}$ [30] [31], $\mathrm{Fe}_{2} \mathrm{O}_{3}$ [31], $\mathrm{Sb}_{2} \mathrm{O}_{3}$ [32], $\mathrm{Cu}$ [8], $\mathrm{Ag}$ [8], Au [8], and electric arc furnace dust [33].

In this study, we prepared samples and conducted thermal tests to study the chemical forms of metals observed during the thermal decomposition and combustion of TBBPA. Mixtures of TBBPA and Pd were prepared, and the TBBPA decomposition behaviour was studied by analysing the $\mathrm{C}$ and $\mathrm{Br}$ concentrations in solid samples and $\mathrm{HBr}$ emissions in the exhaust gas after thermal testing. Investigation of the chemical forms of Pd was primarily based on the results of crystal structure analysis using X-ray diffraction (XRD) and scanning electron microscopy-energy dispersive X-ray spectroscopy (SEM-EDS) elemental mapping images.

\section{Experimental}

\subsection{Samples}

The reagents $\mathrm{Pd}, \mathrm{PdO}, \mathrm{PdBr}_{2}$, and TBBPA $\left(\mathrm{C}_{15} \mathrm{H}_{12} \mathrm{Br}_{4} \mathrm{O}_{2}\right)$ were used to prepare the test samples. Sample mixtures of Pd and TBBPA and PdO and TBBPA were prepared in weight ratios of Pd:TBBPA 1:10.22 and PdO:TBBPA 1:8.89, respectively, and were subjected to thermal testing in an electric furnace. Granular samples were fabricated by subjecting the pulverised mixtures to a pressure of 12 $\mathrm{MPa}$ for $30 \mathrm{~min}$ to form shapes with dimensions of $\varphi=5 \mathrm{~mm}$ and $\mathrm{h}=21 \mathrm{~mm}$. In 
this study, the two prepared mixtures were referred to as Pd + TBBPA and PdO + TBBPA.

\subsection{Thermogravimetry-Differential Thermal Analysis Measurements}

Thermogravimetry-differential thermal analysis (TG-DTA) measurements of the sample mixtures were also performed (Rigaku Co., Ltd. Thermo Plus TG 8120 analyser). First, a $10 \mathrm{mg}$ sample was packed in a $2.5-\mathrm{mm}$-diameter alumina boat and heated from room temperature to $1000^{\circ} \mathrm{C}$ at a rate of $10^{\circ} \mathrm{C} / \mathrm{min}$ under a $\mathrm{He}$ or an $\mathrm{Ar}_{-} \mathrm{O}_{2}(5 \mathrm{~mol} \%)$ environment at $100 \mathrm{~mL} / \mathrm{min}$.

\subsection{Thermal Testing in Electric Furnace}

Figure 1 shows the schematic of the thermal testing equipment. Briefly, $2 \mathrm{~g}$ of each sample (4 granular samples) was packed in an alumina boat and placed at the end of a quartz reaction tube. Simultaneously, gas was passed through the reaction tube, and the electric furnace (Koyo Thermo Systems Co. Ltd. KTF $035 \mathrm{~N}$ ) was heated to a given temperature. Once the rising temperature process was completed, the alumina boat was moved to the centre of the reaction tube and heated for $40 \mathrm{~min}$. The heating temperature was set at $280-800^{\circ} \mathrm{C}$, the gas used was $\mathrm{Ar}$ or $\mathrm{Ar}-\mathrm{O}_{2}$ (5 mol\%), and the gas flow rate was set to $100 \mathrm{~mL} / \mathrm{min}$. The exhaust gases emitted during the thermal test were collected in scrubbed bottles filled with $100 \mathrm{~mL}$ ultra-pure water and hexane.

\subsection{Quantification of Pd, Br, and C in Solid Samples}

After the thermal testing, the granular samples were pulverised using an agate mortar. Subsequently, $0.1 \mathrm{~g}$ of the pulverised sample and $20 \mathrm{~mL}$ of aqua regia were placed in a Teflon container and sealed for dissolution by microwave radiation (Analytic Jena Co., Ltd. TOPwave). Table 1 lists the sample decomposition conditions. Once dissolved, the sample was filtered, and the filtrate was diluted to $100 \mathrm{~mL}$, following which Pd was quantified by inductively coupled plasma-mass spectrometry (Perkin Elmer Co., Ltd. ELAN DRC-e).

Quantification of $\mathrm{Br}$ and $\mathrm{C}$ in the solid samples was performed using an organic halogen sulphur analysis system (Yanaco Co., Ltd. YHS-11) and a micro-corder (J-Science Lab Co., Ltd. JM10), respectively.

\subsection{HBr Quantification}

After the thermal testing, the reaction tube was rinsed with ultra-pure water.

Table 1. Sample decomposition process conditions-microwave decomposition equipment.

\begin{tabular}{ccccc}
\hline & Temperature $\left({ }^{\circ} \mathrm{C}\right)$ & Heatup time $(\mathrm{min})$ & Holding time $(\mathrm{min})$ & Pressue $(\mathrm{bar})$ \\
\hline 1st step & 140 & 15 & 10 & 50 \\
2nd step & 210 & 10 & 45 & 50 \\
\hline
\end{tabular}




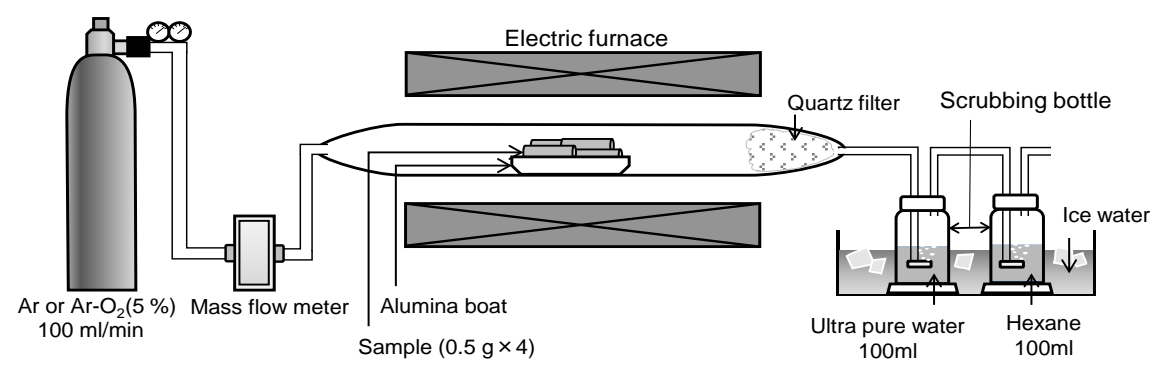

Figure 1. Overview of thermal testing equipment.

Furthermore, the quartz wool was cleaned for $1 \mathrm{~h}$ under ultrasonication in ultra-pure water. These cleaning fluids and ultra-pure water from the gas-scrubing bottles were filtered and diluted to $200 \mathrm{~mL}$ for subsequent analysis. The $\mathrm{Br}$ in the solution was quantified using ion chromatography (Dionex Co., Ltd. DX-120) and converted into $\mathrm{HBr}$.

\subsection{Crystal Structure Analysis}

The crystal structure of the solid samples was determined by XRD (Bruker Co., Ltd. D8 ADVANCE/L). Table 2 lists the XRD measurement conditions.

\subsection{Elemental Mapping}

Elemental mapping images of the sample surface were obtained using field-emission SEM-EDS (JEOL Co., Ltd. JSM 7100F). In preparation for the SEM observations, a cross-section polisher was used to apply an Ar-ion beam sputter to the sample surface and expose the particle cross-sections.

\section{Results and Discussion}

\subsection{Analysis of Pyrolytic and Oxidative Decomposition}

Figure 2 shows the TG curves of the Pd + TBBPA and PdO + TBBPA samples and of the reagents $\mathrm{PdO}, \mathrm{PdBr}_{2}$, and TBBPA in a He atmosphere. At $200^{\circ} \mathrm{C}$, rapid weight loss was observed for the Pd + TBBPA sample, with the weight loss rate reaching $64 \%$ at $310^{\circ} \mathrm{C}$. Since this weight loss behaviour was virtually identical to that of TBBPA in this temperature range, it was believed that TBBPA volatilisation or decomposition occurred. The weight loss rate at $310^{\circ} \mathrm{C}-560^{\circ} \mathrm{C}$ was $6.0 \%$. Because the weight loss behaviours for $\mathrm{PdO}$ and $\mathrm{PdBr}_{2}$ were different, this loss was probably caused by another compound. A small weight loss was also observed at $560^{\circ} \mathrm{C}-690^{\circ} \mathrm{C}$, but hardly any change was observed above $690^{\circ} \mathrm{C}$, with a total weight loss rate of $69 \%$ achieved by the end of the test. For the PdO + TBBPA sample, the weight loss rate was $33.9 \%$ when the temperature was increased to $310^{\circ} \mathrm{C}$. In this temperature range, the weight loss behaviour was similar to that of the Pd + TBBPA sample. However, from $350^{\circ} \mathrm{C}$ to $730^{\circ} \mathrm{C}$, weight loss occurred at a nearly constant rate, differing substantially from the behaviour of the Pd + TBBPA sample. Furthermore, this weight loss behaviour did not correspond to those of the other two reagents $\left(\mathrm{PdO}\right.$ and $\left.\mathrm{PdBr}_{2}\right)$ in this 


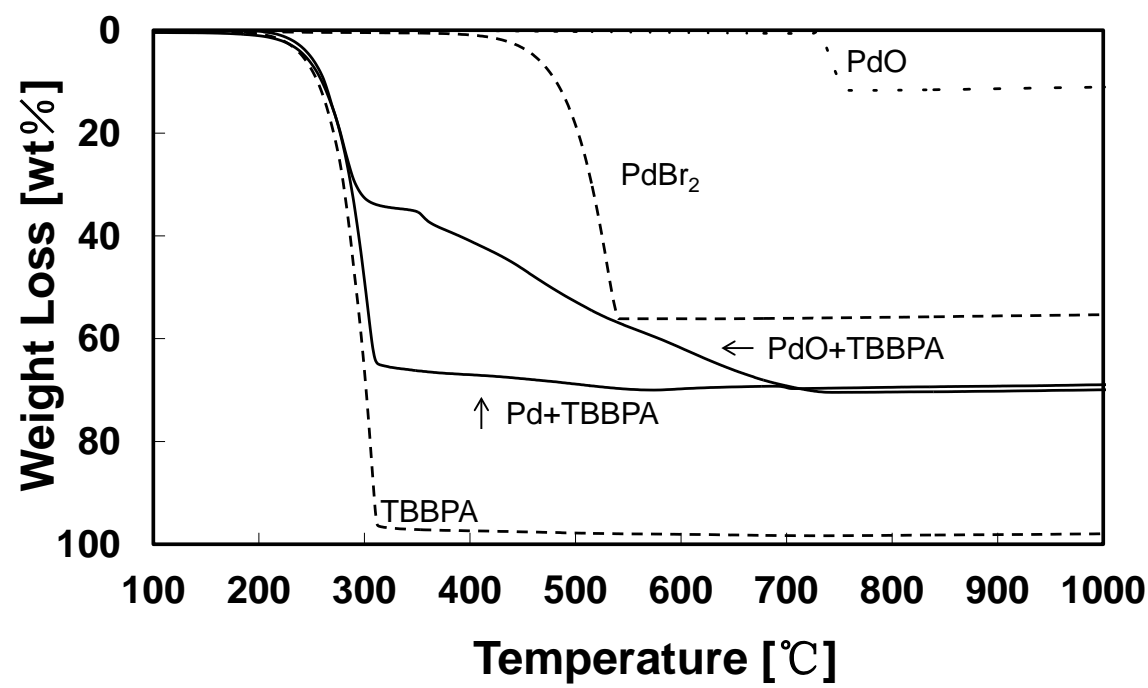

Figure 2. TG curves of Pd + TBBPA and PdO + TBBPA samples and of PdO, $\mathrm{PdBr}_{2}$, and TBBPA in He atmosphere.

Table 2. XRD measurement conditions.

\begin{tabular}{cc}
\hline Voltage $(\mathrm{kV})$ & 40 \\
Current (mA) & 40 \\
start angle (deg.) & 10 \\
stop angle (deg.) & 80 \\
step angle (deg.) & 0.02 \\
\hline
\end{tabular}

temperature range. The total weight loss at $730^{\circ} \mathrm{C}$ was $70.3 \%$, almost identical to that of the Pd + TBBPA sample.

Figure 3 shows the TG curves of the Pd + TBBPA sample in $\mathrm{Ar}-\mathrm{O}_{2}$ and $\mathrm{He}$ atmospheres, and the same comparison is made for the PdO + TBBPA sample in Figure 4. The TG curves for the Pd + TBBPA sample were nearly identical, and no major atmospheric-induced differences were observed. In addition, the TG curves were consistent for the PdO + TBBPA sample up to $470^{\circ} \mathrm{C}$. Subsequently, the mass of the sample gradually decreased until $730^{\circ} \mathrm{C}$ in the He atmosphere and rapidly decreased until $590^{\circ} \mathrm{C}$ in the $\mathrm{Ar}-\mathrm{O}_{2}$ atmosphere, and remained nearly constant afterwards, although slight rises and falls were observed.

\subsection{Pd Bromination Accompanying TBBPA Decomposition}

\subsubsection{Solid/Gas Distribution of Pd, Br, and C}

\section{1) Ar atmosphere}

The mass balance of $\mathrm{Pd}, \mathrm{C}$, and $\mathrm{Br}$ before and after heating is shown in Figure 5(a) for the Pd + TBBPA sample and in Figure 5(b) for the PdO + TBBPA sample. For the Pd + TBBPA sample, Pd volatilisation through heating was not observed. Considering the TG results (Figure 2) and the initial Pd content of 28 $\mathrm{wt} \%$, it could be inferred that the main residue in the sample at temperatures over $690^{\circ} \mathrm{C}$ was $\mathrm{Pd}$. However, the balance of $\mathrm{C}$ and $\mathrm{Br}$ was different from that of 


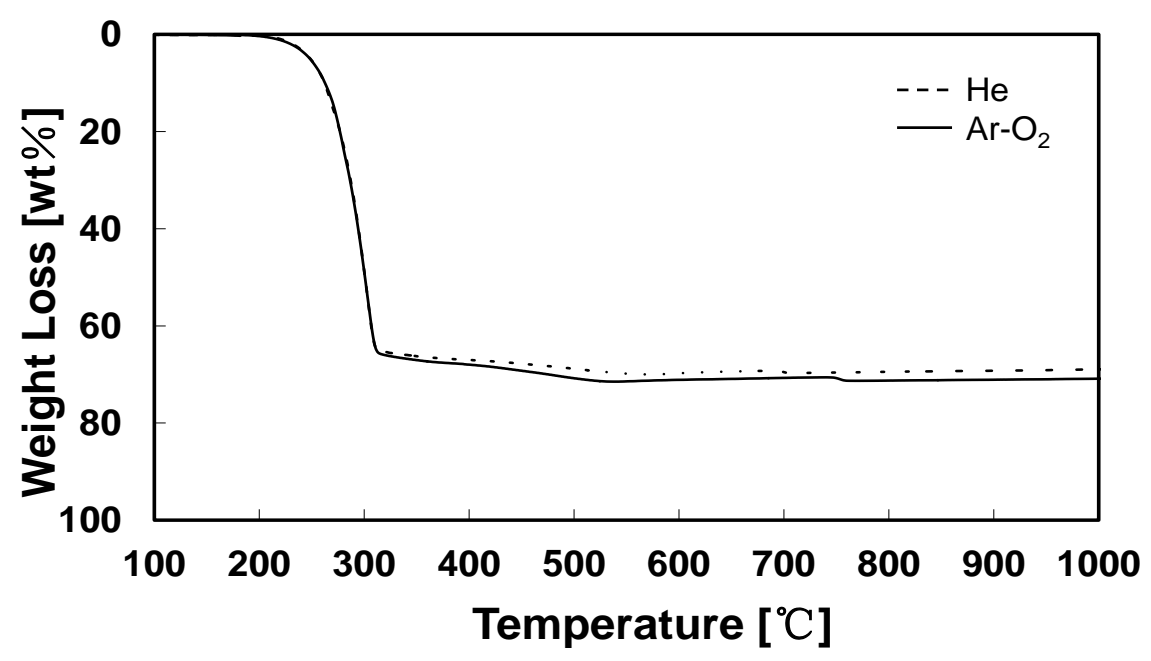

Figure 3. TG curves of $\mathrm{Pd}+\mathrm{TBBPA}$ and $\mathrm{PdO}+\mathrm{TBBPA}$ samples and of $\mathrm{PdO}, \mathrm{PdBr}_{2}$, and TBBPA in He atmosphere.

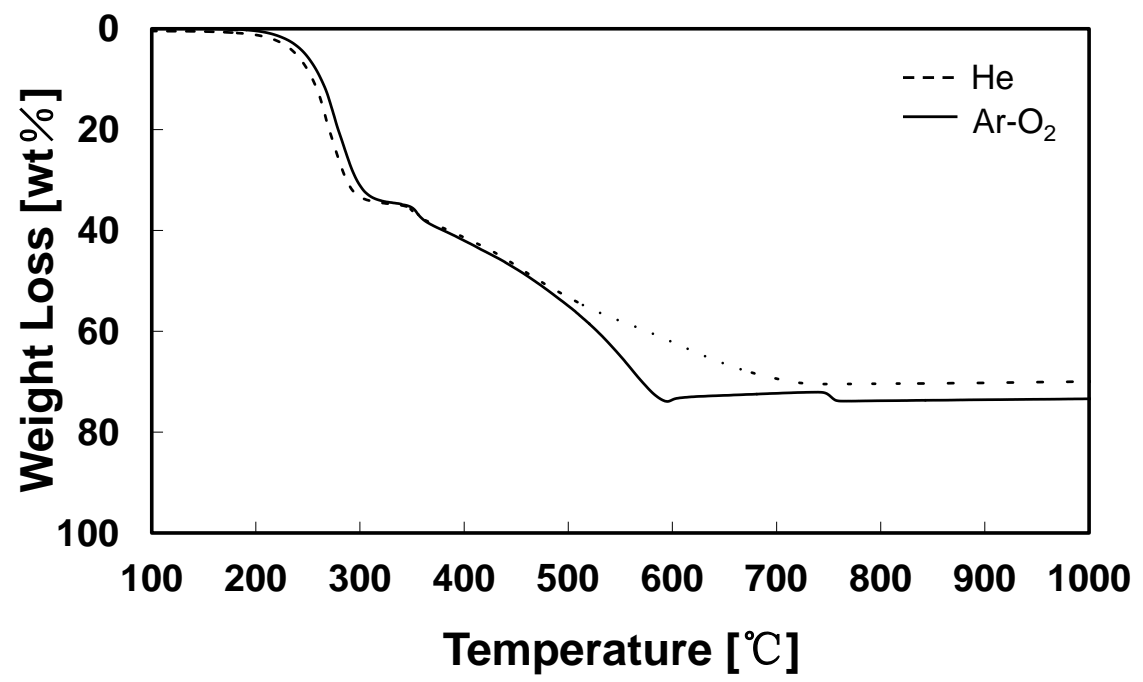

Figure 4. TG curves of $\mathrm{PdO}+\mathrm{TBBPA}$ sample in $\mathrm{Ar}-\mathrm{O}_{2}$ and $\mathrm{He}$ atmospheres.

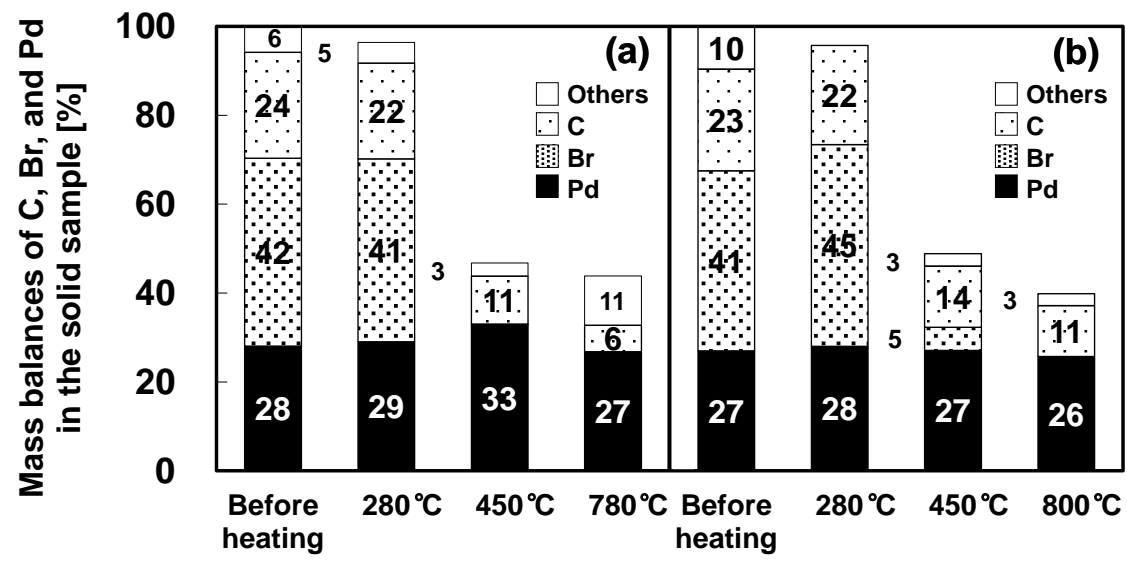

Figure 5. Pd, C, and Br mass balances before and after heating for (a) Pd + TBBPA and (b) PdO + TBBPA samples in Ar atmosphere. 
$\mathrm{Pd}$. The residual rates of $\mathrm{C}$ in the solid samples decreased with increasing temperature and the values were $89.3 \%, 44.3 \%$, and $25.5 \%$ at $280^{\circ} \mathrm{C}, 450^{\circ} \mathrm{C}$, and $780^{\circ} \mathrm{C}$, respectively. For $\mathrm{Br}$, the residual rate was $96.1 \%$ at $280^{\circ} \mathrm{C}$, which decreased to $0.49 \%$ at $450^{\circ} \mathrm{C}$, and by $780^{\circ} \mathrm{C}, \mathrm{Br}$ had completely volatilised.

For the PdO + TBBPA sample, $13.0 \% \mathrm{Br}$ residual content was observed at $450^{\circ} \mathrm{C}$, which was higher than the $0.49 \%$ content observed in the Pd + TBBPA sample. The $\mathrm{Br}$ volatilisation rate slowed down because of the presence of $\mathrm{PdO}$, and it was surmised that decomposition occurred after Pd bromide was produced.

\section{2) $\mathrm{Ar}-\mathrm{O}_{2}$ atmosphere}

$\mathrm{Pd}, \mathrm{C}$, and $\mathrm{Br}$ balances before and after heating are shown in Figure 6(a) for the Pd + TBBPA sample and in Figure 6(b) for the PdO + TBBPA sample. The $\mathrm{Br}$ volatilisation rate in the $\mathrm{Pd}+\mathrm{TBBPA}$ sample at $280^{\circ} \mathrm{C}$ was significantly higher than that in the Ar atmosphere. No other atmospheric-induced differences were observed.

\subsubsection{TBBPA to $\mathrm{HBr}$ Conversion Ratio}

\section{1) Ar atmosphere}

Figure 7 shows the relationship between the heating temperature of the $\mathrm{Pd}+$ TBBPA and $\mathrm{PdO}+$ TBBPA samples and their respective $\mathrm{HBr}$ conversion rates. The $\mathrm{HBr}$ conversion rate of the $\mathrm{Pd}+\mathrm{TBBPA}$ sample was $2.5 \%$ at $280^{\circ} \mathrm{C}$ and increased to $24.7 \%$ at $450^{\circ} \mathrm{C}$. Because all $\mathrm{Br}$ in the solid sample volatilised at $450^{\circ} \mathrm{C}$, it was believed that $\mathrm{HBr}$ represented $25 \%$ of the chemical form of bromine, with the remainder occurring as $\mathrm{Br}_{2}$ or organ bromide compounds. The $\mathrm{HBr}$ conversion rate was $25.6 \%$ at $780^{\circ} \mathrm{C}$, nearly identical to that at $450^{\circ} \mathrm{C}$. The $\mathrm{HBr}$ conversion rate in the $\mathrm{PdO}+\mathrm{TBBPA}$ sample at $280^{\circ} \mathrm{C}$ was low $(0.7 \%)$, similar to that of the Pd + TBBPA sample. However, not only were the rates higher than those for the Pd + TBBPA sample, $63.7 \%$ at $450^{\circ} \mathrm{C}$ and $72.7 \%$ at $800^{\circ} \mathrm{C}$, but they increased as a function of temperature. This indicated that TBBPA thermal decomposition differed substantially in the presence of Pd and PdO.

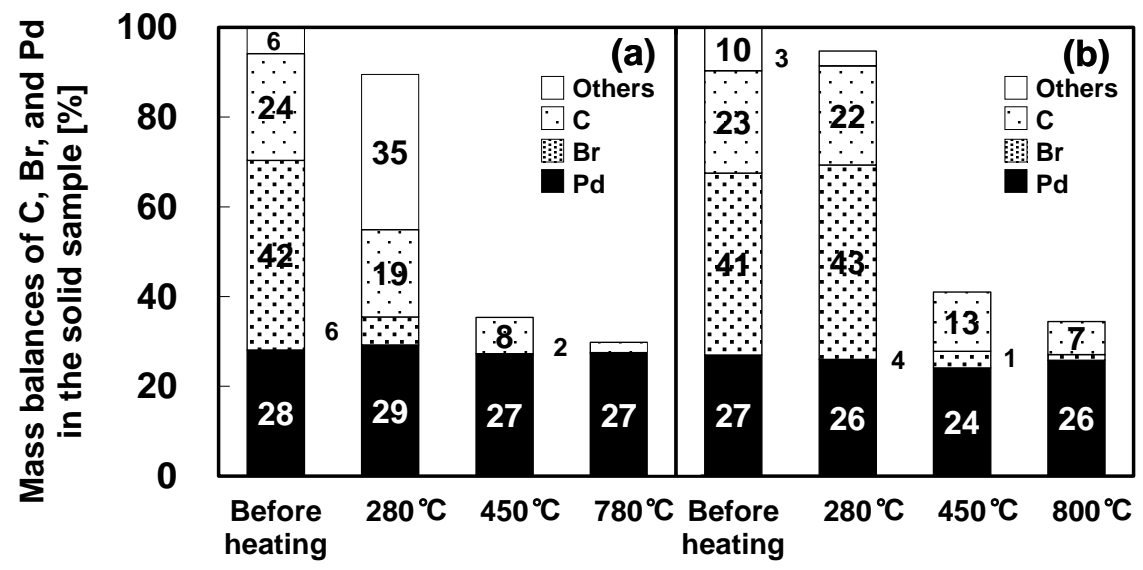

Figure 6. Pd, C, and $\mathrm{Br}$ mass balances before and after heating for (a) Pd + TBBPA and (b) $\mathrm{PdO}+\mathrm{TBBPA}$ samples in $\mathrm{Ar}-\mathrm{O}_{2}$ atmosphere. 


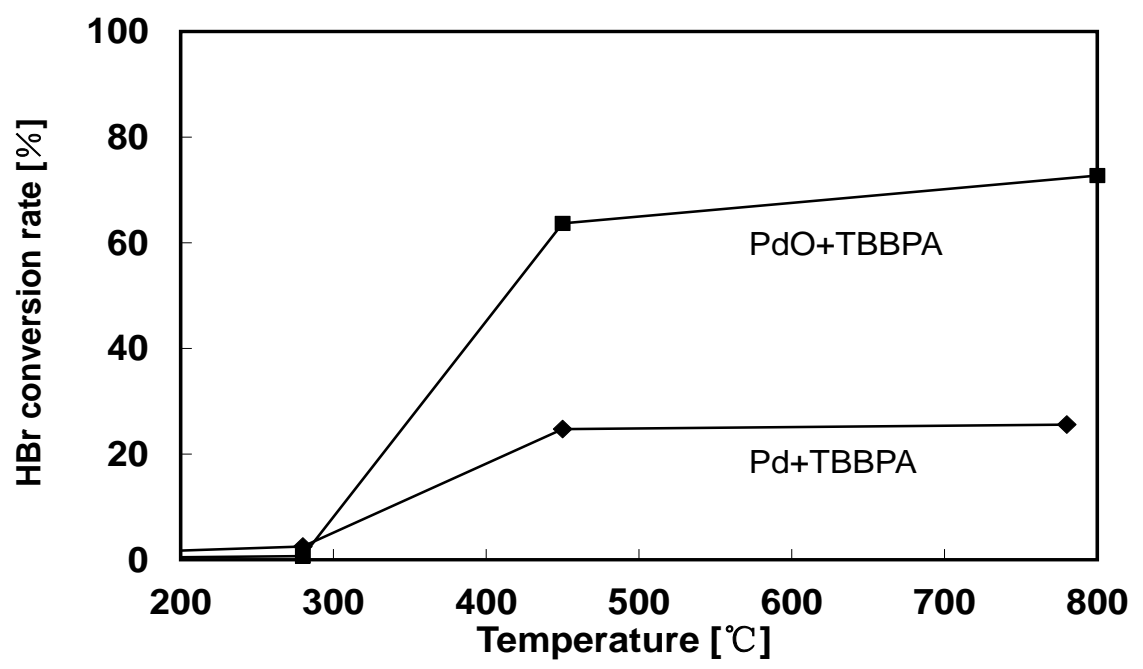

Figure 7. Pd, C, and Br mass balances before and after heating for (a) Pd + TBBPA and (b) $\mathrm{PdO}+\mathrm{TBBPA}$ samples in $\mathrm{Ar}-\mathrm{O}_{2}$ atmosphere.

\section{2) $\mathrm{Ar}-\mathrm{O}_{2}$ atmosphere}

Figure 8 shows the relationship between heating temperatures of the $\mathrm{Pd}+$ TBBPA and PdO + TBBPA samples and their respective $\mathrm{HBr}$ conversion rates. The $\mathrm{HBr}$ conversion rates for the $\mathrm{Pd}+\mathrm{TBBPA}$ sample were $1.4 \%$ and $30.7 \%$ at 280 and $450^{\circ} \mathrm{C}$, respectively. The rate substantially increased to $67.2 \%$ at $780^{\circ} \mathrm{C}$ (nearly twice) in an inert atmosphere. This indicated that when Pd was present, oxygen in the atmosphere promoted $\mathrm{HBr}$ conversion in TBBPA.

The $\mathrm{HBr}$ conversion rates in the $\mathrm{PdO}+\mathrm{TBBPA}$ sample were $51.6 \%$ and $57.4 \%$ at 450 and $800^{\circ} \mathrm{C}$, respectively, with higher values in the inert atmosphere under identical temperature conditions. When $\mathrm{PdO}$ was present, $\mathrm{HBr}$ conversion rates were lower than that in the inert atmosphere at temperatures greater than $450^{\circ} \mathrm{C}$ due to the presence of oxygen, and the impact on $\mathrm{Br}_{2}$ production was likely substantial.

\subsubsection{Crystal Structure Analysis Using XRD}

\section{1) Ar atmosphere}

Figure 9(a) and Figure 9(b) show the XRD patterns for the Pd + TBBPA and PdO + TBBPA samples, respectively. For the Pd + TBBPA sample, at $280^{\circ} \mathrm{C}$, in addition to a clear Pd peak, peaks arising from TBBPA and its decomposition products were observed in the $2 \theta$ range $10.4^{\circ}-38.3^{\circ}$. However, at $450^{\circ} \mathrm{C}$ and higher, only Pd peaks were detected.

For the $\mathrm{PdO}+\mathrm{TBBPA}$ sample, at $280^{\circ} \mathrm{C}$, peaks originating from TBBPA decomposition products could be observed at $2 \theta=14.0^{\circ}$ and $22.7^{\circ}-24.1^{\circ}$. Furthermore, both $\mathrm{PdO}$ and Pd peaks were detected. Since the thermal decomposition of $\mathrm{PdO}$ to $\mathrm{Pd}$ occurred at $750^{\circ} \mathrm{C}$ or higher (Figure 2), $\mathrm{PdO}$ reduction reactions with TBBPA decomposition products occurred. The PdO peaks disappeared at $450^{\circ} \mathrm{C}$ and $800^{\circ} \mathrm{C}$, and only Pd peaks could be confirmed.

\section{2) $\mathrm{Ar}-\mathrm{O}_{2}$ atmosphere}




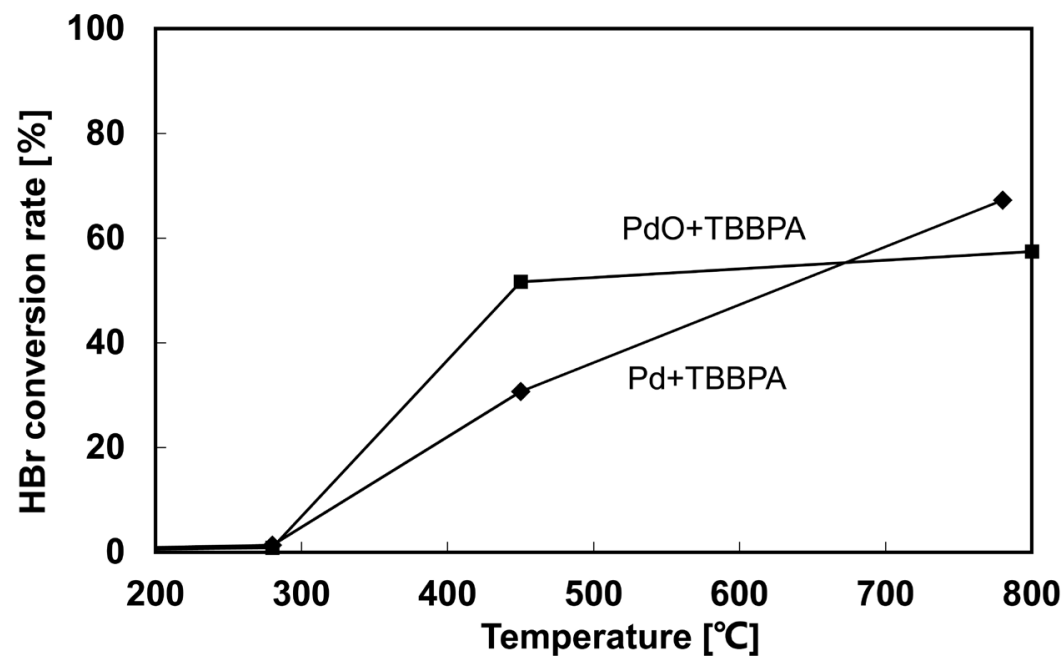

Figure 8. Relation between heating temperature and $\mathrm{HBr}$ conversion rate in $\mathrm{Pd}+\mathrm{TBBPA}$ and $\mathrm{PdO}+$ TBBPA samples in $\mathrm{Ar}-\mathrm{O}_{2}$ atmosphere.

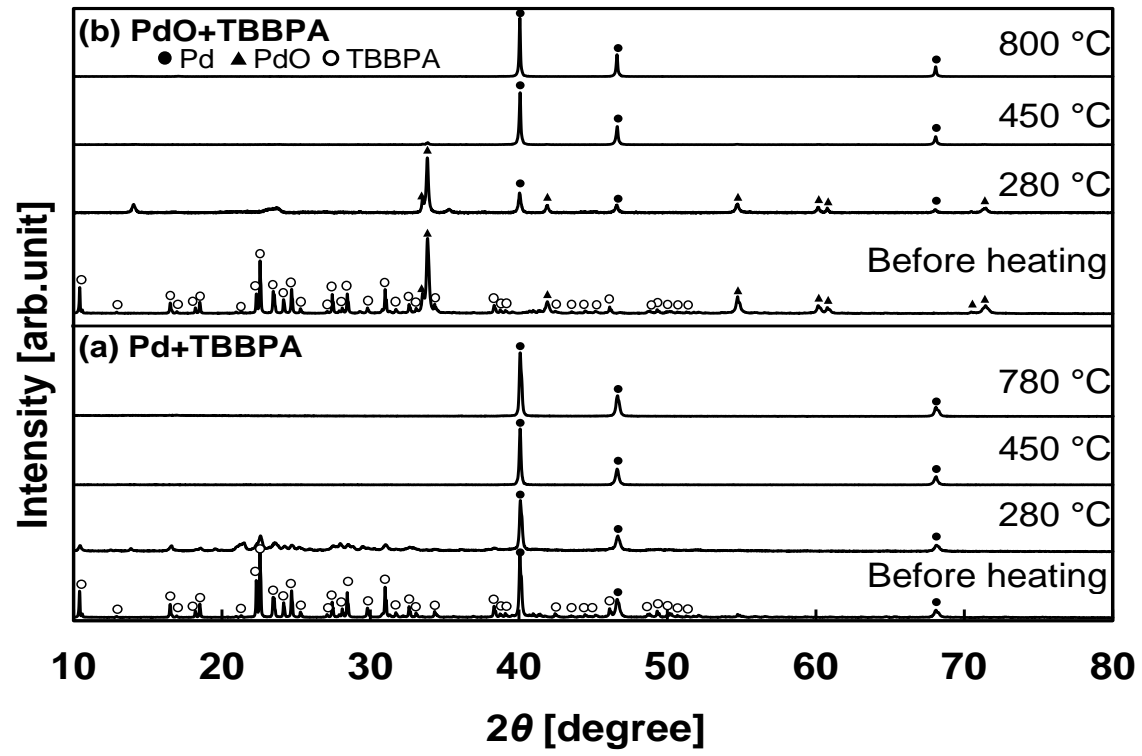

Figure 9. XRD patterns of (a) Pd + TBBPA and (b) PdO + TBBPA samples in Ar atmosphere.

Figure 10(a) and Figure 10(b) show the XRD patterns for the Pd + TBBPA and $\mathrm{PdO}+$ TBBPA samples, respectively. The peaks originating from the TBBPA decomposition products and Pd were observed for the Pd + TBBPA sample at $280^{\circ} \mathrm{C}$. Similar to observations in the Ar atmosphere, only Pd peaks were detected at 450 or $780^{\circ} \mathrm{C}$. The XRD patterns of the PdO + TBBPA sample were similar to those obtained in the Ar atmosphere, and no significant atmospheric-induced differences were observed in terms of the chemical form of Pd.

\subsubsection{Pd and Br Elemental Mapping}

\section{1) Ar Atmosphere}




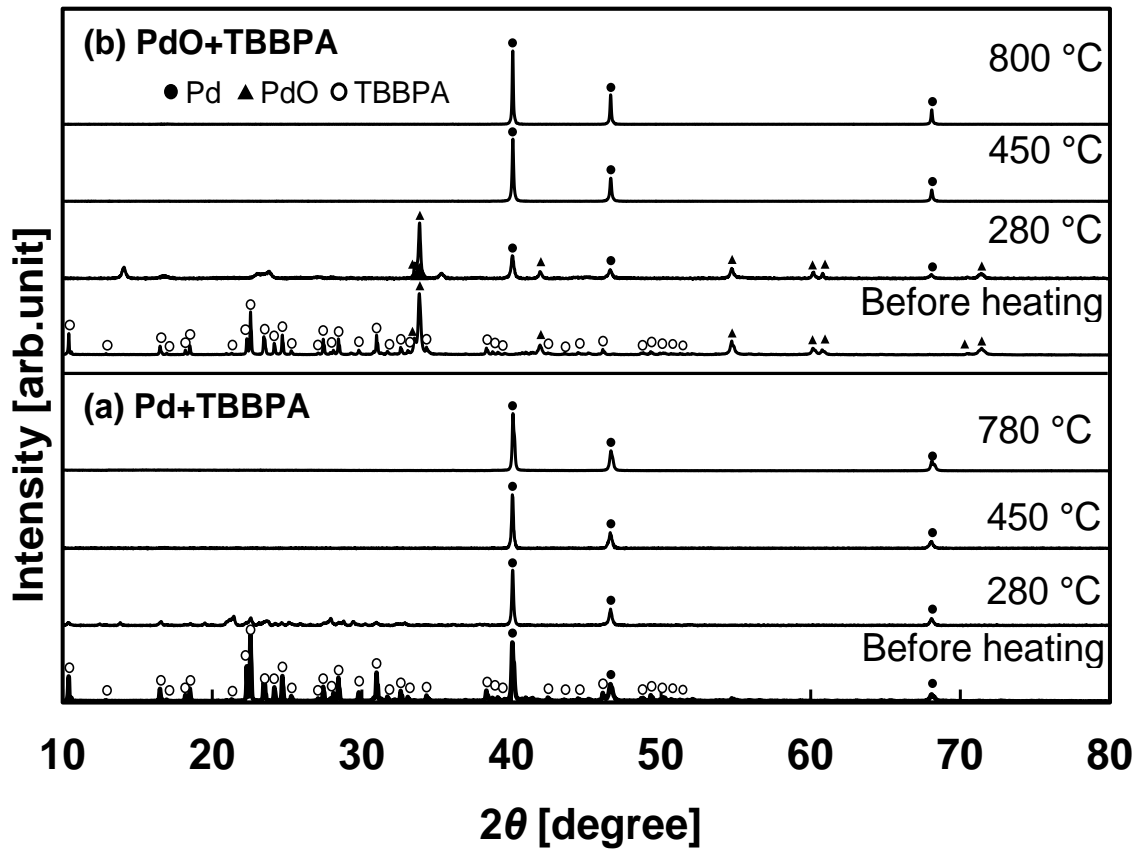

Figure 10. XRD patterns of (a) Pd + TBBPA and (b) PdO + TBBPA samples in $A r-\mathrm{O}_{2}$ atmosphere.

Figure 11(a) and Figure 11(b) show the SEM images and Pd and Br elemental mapping of the Pd + TBBPA and PdO + TBBPA samples, respectively, before and after heating. Table 3 lists the semi-quantitative analysis results for Pd and $\mathrm{Br}$ obtained by SEM-EDS. The presence of $\mathrm{Pd}$ and $\mathrm{Br}$ was clearly confirmed in the Pd + TBBPA sample before heating and at $280^{\circ} \mathrm{C}$, although the images did not perfectly overlap. Br was believed to exist primarily in the form of an organic compound, which was consistent with the XRD results (Figure 9(a)). However, only Pd was observed at temperatures greater than $450^{\circ} \mathrm{C}$.

For the $\mathrm{PdO}+\mathrm{TBBPA}$ sample, at $280^{\circ} \mathrm{C}$, no significant difference with respect to the Pd + TBBPA sample was observed in the $\mathrm{Pd}$ and $\mathrm{Br}$ mapping images. However, in addition to the comparatively high concentration of $\mathrm{Br}(7.3 \%)$ at $450^{\circ} \mathrm{C}$, partial overlap of $\mathrm{Pd}$ and $\mathrm{Br}$ was observed. This suggested that Pd bromide compounds were present, and that Pd bromination reactions occurred between $280^{\circ} \mathrm{C}$ and $450^{\circ} \mathrm{C}$. As shown in the TG curves (Figure 2), weight loss occurred at a nearly constant rate between $350^{\circ} \mathrm{C}$ and $730^{\circ} \mathrm{C}$, which was likely caused by bromide decomposition. This was confirmed by the absence of $\mathrm{Br}$ at $800^{\circ} \mathrm{C}$ and the sole presence of $\mathrm{Pd}$.

2) $\mathrm{Ar}-\mathrm{O}_{2}$ Atmosphere

Figure 12(a) and Figure 12(b) show the SEM images and $\mathrm{Pd}$ and $\mathrm{Br}$ elemental mapping images of the Pd + TBBPA and PdO + TBBPA samples, respectively, before and after heating. Table 4 lists the semi-quantitative analysis results for Pd and Br obtained by SEM-EDS. Similar to the results in the Ar atmosphere, $\mathrm{Pd}$ and $\mathrm{Br}$ were present at $280^{\circ} \mathrm{C}$, although the mapping images did not overlap. Furthermore, no $\mathrm{Br}$ was observed at $450^{\circ} \mathrm{C}$ or $780^{\circ} \mathrm{C}$. 


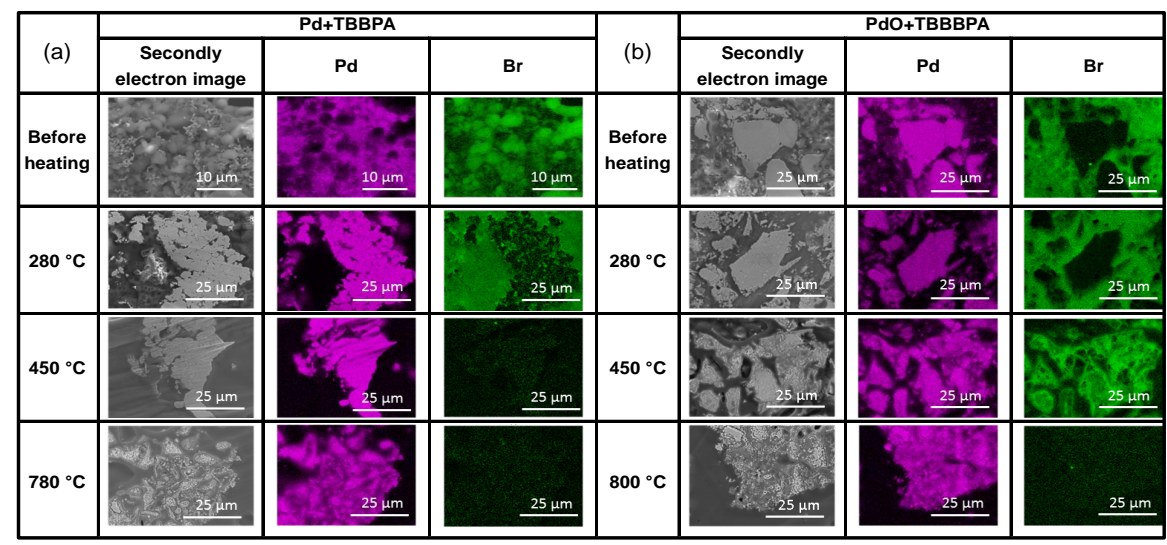

Figure 11. SEM images and $\mathrm{Pd} / \mathrm{Br}$ elemental mapping images before and after heating for (a) Pd + TBBPA and (b) PdO + TBBPA in Ar atmosphere.

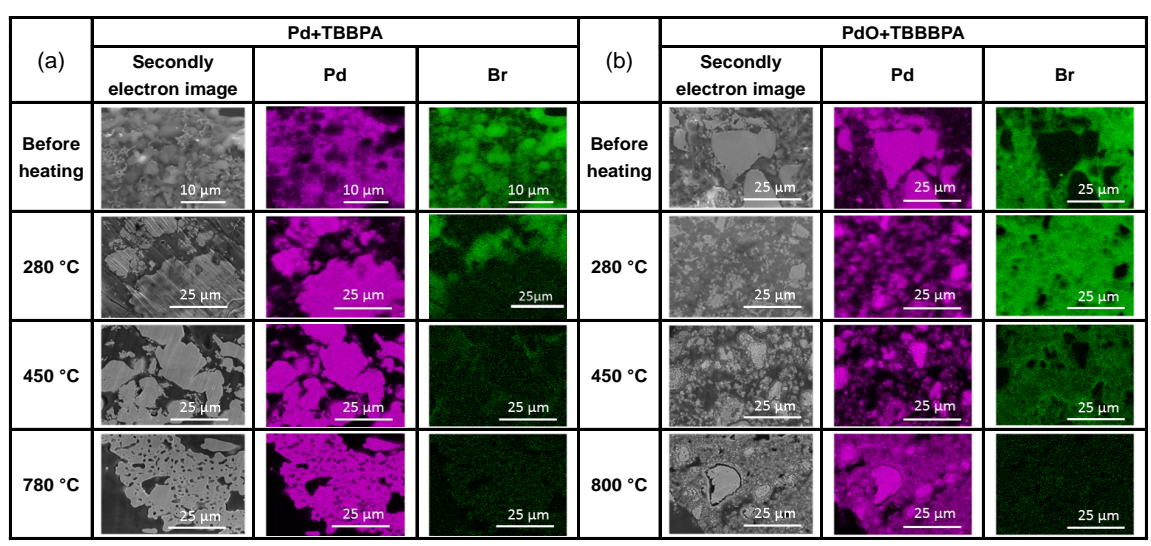

Figure 12. SEM images and $\mathrm{Pd} / \mathrm{Br}$ elemental mapping images before and after heating for (a) $\mathrm{Pd}+\mathrm{TBBPA}$ and (b) $\mathrm{PdO}+\mathrm{TBBPA}$ in $\mathrm{Ar}-\mathrm{O}_{2}$ atmosphere.

Table 3. Semi-quantitative analysis results for $\mathrm{Pd}$ and $\mathrm{Br}$ concentrations using SEM-EDS in Ar atmosphere.

\begin{tabular}{cccc}
\hline & & $\operatorname{Pd}(\mathrm{wt} \%)$ & $\mathrm{Br}(\mathrm{wt} \%)$ \\
\hline \multirow{2}{*}{$\mathrm{Pd}+\mathrm{TBBPA}$} & $280^{\circ} \mathrm{C}$ & 48 & 10 \\
& $450^{\circ} \mathrm{C}$ & 49 & 4 \\
$780^{\circ} \mathrm{C}$ & 27 & 0.05 \\
& 32 & 0.07 \\
$\mathrm{PdO}+\mathrm{TBBPA}$ & $280^{\circ} \mathrm{C}$ & 41 & 9.3 \\
& $450^{\circ} \mathrm{C}$ & 30 & 30 \\
& $800^{\circ} \mathrm{C}$ & 32 & 7.3 \\
& & 33 & 0.15 \\
\hline
\end{tabular}

Although $\mathrm{Pd}$ and $\mathrm{Br}$ were present up to $280^{\circ} \mathrm{C}$ in the $\mathrm{PdO}+\mathrm{TBBPA}$ sample, no overlap of the mapping images was observed. The $\mathrm{Br}$ concentration was 5.0\% at $450^{\circ} \mathrm{C}$, but no areas were observed with a clear overlap of $\mathrm{Pd}$ and $\mathrm{Br}$ mapping images. As in the inert atmosphere, only Pd was detected at $800^{\circ} \mathrm{C}$. 
Table 4. Semi-quantitative analysis results for $\mathrm{Pd}$ and $\mathrm{Br}$ concentrations using SEM-EDS in $\mathrm{Ar}-\mathrm{O}_{2}$ atmosphere.

\begin{tabular}{cccc}
\hline & & Pd (wt\%) & Br (wt\%) \\
\hline Before Heating & 48 & 10 \\
$280^{\circ} \mathrm{C}$ & 48 & 1.4 \\
$450^{\circ} \mathrm{C}$ & 64 & 0.4 \\
$780^{\circ} \mathrm{C}$ & 61 & 0.14 \\
& Before Heating & 41 & 9.3 \\
PdO + TBBPA & $280^{\circ} \mathrm{C}$ & 16 & 36 \\
& $450^{\circ} \mathrm{C}$ & 34 & 5.0 \\
& $800^{\circ} \mathrm{C}$ & 50 & 0.26 \\
\hline
\end{tabular}

\section{Conclusions}

In this study, thermal testing of TBBPA and Pd/PdO mixtures (Pd + TBBPA and PdO + TBBPA) was conducted to study the chemical form of Pd obtained during TBBPA pyrolytic and oxidative decomposition and combustion.

In the pyrolytic test of the Pd + TBBPA sample, Pd bromination did not occur. Furthermore, Pd primarily existed as a metal, regardless of the temperature conditions or the presence of oxygen. In the PdO + TBBPA sample, SEM-EDS indicated that $\mathrm{Pd}$ bromide was present in the solid samples obtained in an $\mathrm{Ar}$ atmosphere at $450^{\circ} \mathrm{C}$. The absence of $\mathrm{Pd}$ bromide at $280^{\circ} \mathrm{C}$ suggested that the bromination reaction occurred at $280^{\circ} \mathrm{C}-450^{\circ} \mathrm{C}$. Weight loss occurred at an almost constant rate, as indicated by TG-DTA, between $350^{\circ} \mathrm{C}$ and $730^{\circ} \mathrm{C}$, indicating that $\mathrm{Pd}$ bromide decomposed in this temperature range.

\section{Acknowledgements}

This work was supported by JSPS KAKENHI Grant Number 16K00664, and by the Cooperative Research Program of "Network Joint Research Center for Materials and Devices," and by the High Efficiency Rare Elements Extraction Technology Area in the Tohoku Innovation Materials Technology Initiatives for Reconstruction from the Ministry of Education, Culture, Sports, Science and Technology in Japan.

\section{References}

[1] Ogunseitan, A.O. (2013) The Basel Convention and e-Waste: Translation of Scientific Uncertainty to Protective Policy. The Lancet Global Health, 1, 313-314. https://doi.org/10.1016/S2214-109X(13)70110-4

[2] Huang, K., Guo, J. and Xu, Z. (2009) Recycling of Waste Printed Circuit Boards: A Review of Current Technologies and Treatment Status in China. Journal of Hazardous Materials, 164, 399-408. https://doi.org/10.1016/j.jhazmat.2008.08.051

[3] Cui, J. and Forssberg, E. (2007) Characterisation of Shredded Television Scrap and Implications for Materials Recovery. Waste Management, 27, 415-424. https://doi.org/10.1016/j.wasman.2006.02.003 
[4] Ilyas, S., Anwar, M., Niazi, S.B. and Ghauri, M.A. (2007) Bioleaching of Metals from Electronic Scrap by Moderately Thermophilic Acidophilic Bacteria. Hydrometallurgy, 88, 180-188. https://doi.org/10.1016/j.hydromet.2007.04.007

[5] Christian, H. (2006) Recycling of Electronic Scrap at Umicore's Integrated Metals Smelter and Refinery. World of Metallurgy-ERZMETALL, 59, 152-161.

[6] Yang, H., Liu, J. and Yang, J. (2011) Leaching Copper from Shredded Particles of Waste Printed Circuit Boards. Journal of Hazardous Materials, 187, 393-400. https://doi.org/10.1016/j.jhazmat.2011.01.051

[7] Oh, C.J., Lee, S.O., Yang, H.K., Ha, T.J. and Kim, M.J. (2003) Selective Leaching of Valuable Metals from Waste Printed Circuit Boards. Journal of the Air \& Waste Management Association, 53, 897-902. https://doi.org/10.1080/10473289.2003.10466230

[8] Oleszek, S., Grabda, M., Shibata, E. and Nakamura, T. (2013) Distribution of Copper, Silver and Gold during Thermal Treatment with Brominated Flame Retardants. Waste Management, 33, 1835-1842. https://doi.org/10.1016/j.wasman.2013.05.009

[9] Yang, Y., Chen, S., Li, S., Chen, M., Chen, H. and Liu, B. (2014) Bioleaching Waste Printed Circuit Boards by Acidithiobacillus Ferrooxidans and Its Kinetics Aspect. Journal of Biotechnology, 173, 24-30. https://doi.org/10.1016/j.jbiotec.2014.01.008

[10] Xiu, F.-R., Weng, H., Qi, Y., Yu, G., Zhang, Z. and Zhang, F.-S. (2016) A Novel Reutilisation Method for Waste Printed Circuit Boards as flame Retardant and Smoke Suppressant for poly (vinyl chloride). Journal of Hazardous Materials, 315, 102-109. https://doi.org/10.1016/j.jhazmat.2016.04.076

[11] Xiu, F.-R. and Zhang, F.-S. (2010) Materials Recovery from Waste Printed Circuit Boards by Supercritical Methanol. Journal of Hazardous Materials, 178, 628-634. https://doi.org/10.1016/j.jhazmat.2010.01.131

[12] Duan, C.L., Diao, Z.J., Zhao, Y.M. and Huang, W. (2015) Liberation of Valuable Materials in Waste Printed Circuit Boards by High-Voltage Electrical Pulses. Minerals Engineering, 70, 170-177. https://doi.org/10.1016/j.mineng.2014.09.018

[13] Serpe, A., Artizzu, F., Mercuri, M.L., Pilia, L. and Deplano, P. (2008) Charge Transfer Complexes of Dithioxamides with Dihalogens as Powerful Reagents in the Dissolution of Noble Metals. Coordination Chemistry Reviews, 252, 1200-1212. https://doi.org/10.1016/j.ccr.2008.01.024

[14] Ortuño, N., Moltó, J., Conesa, J.A. and Font, R. (2014) Formation of Brominated Pollutants during the Pyrolysis and Combustion of Tetrabromobisphenol A at Different Temperatures. Environmental Pollution, 191, 31-37. https://doi.org/10.1016/j.envpol.2014.04.006

[15] Lin, K.-H. and Chiang, H.-L. (2014) Liquid Oil and Residual Characteristics of Printed Circuit Board Recycle by Pyrolysis. Journal of Hazardous Materials, 271, 258-265. https://doi.org/10.1016/j.jhazmat.2014.02.031

[16] Chiang, H.-L. and Lin, K.-H. (2014) Exhaust Constituent Emission Factors of Printed Circuit Board Pyrolysis Processes and Its Exhaust Control. Journal of Hazardous Materials, 264, 545-551. https://doi.org/10.1016/j.jhazmat.2013.10.049

[17] Han, S.-K., Bilski, P., Karriker, B., Sik, R.H. and Chignell, C.F. (2008) Oxidation of Flame Retardant Tetrabromobisphenol A by Singlet Oxygen. Environmental Science \& Technology, 42, 166-172. https://doi.org/10.1021/es071800d

[18] Blazsó, M. and Czégény, Z. (2006) Catalytic Destruction of Brominated Aromatic Compounds Studied in a Catalyst Microbed Coupled to Gas Chromatography/Mass Spectrometry. Journal of Chromatography A, 1130, 91-96. https://doi.org/10.1016/j.chroma.2006.05.009 
[19] Luda, M.P., Balabanovich, A.I., Hornung, A. and Camino, G. (2003) Thermal Degradation of a Brominated Bisphenol A Derivative. Polymers for Advanced Technologies, 14, 741-748. https://doi.org/10.1002/pat.389

[20] Chien, Y.-C., Wang, H.P., Lin, K.S., Huang, Y.-J. and Yang, Y.W. (2000) Fate of Bromine in Pyrolysis of Printed Circuit Board Wastes. Chemosphere, 40, 383-387. https://doi.org/10.1016/S0045-6535(99)00251-9

[21] Liu, W.-J., Tian, K., Jiang, H. and Yu, H.-Q. (2016) Lab-Scale Thermal Analysis of Electronic Waste Plastics. Journal of Hazardous Materials, 310, 217-225. https://doi.org/10.1016/j.jhazmat.2016.02.044

[22] Matsuura, H. and Tsukihashi, F. (2006) Chlorination Kinetics of $\mathrm{ZnO}$ with Ar- $-\mathrm{Cl}_{2}-\mathrm{O}_{2}$ Gas and the Effect of Oxychloride Formation. Metallurgical and Materials Transactions B, 37, 413-420. https://doi.org/10.1007/s11663-006-0026-7

[23] Matsuura, M., Hamano, T. and Tsukihashi, F. (2006) Chlorination Kinetics of $\mathrm{ZnFe}_{2} \mathrm{O}_{4}$ with Ar- $\mathrm{Cl}_{2}-\mathrm{O}_{2}$ Gas. Materials Transactions, 47, 2524-2532.

[24] Zhang, B., Yan, X.-Y., Shibata, K., Uda, T., Tada, M. and Hirasawa, M. (2000) Thermogravimetric-Mass Spectrometric Analysis of the Reactions between Oxide $\left(\mathrm{ZnO}, \mathrm{Fe}_{2} \mathrm{O}_{3}\right.$ or $\mathrm{ZnFe}_{2} \mathrm{O}_{4}$ ) and Polyvinyl Chloride under Inert Atmosphere. Materials Transactions, 41, 1342-1350.

[25] Grabda, M., Oleszek-Kudlak, S., Shibata, E. and Nakamura, T. (2011) Vaporisation of Zinc during Thermal Treatment of $\mathrm{ZnO}$ with Tetrabromobisphenol A (TBBPA). Journal of Hazardous Materials, 187, 473-479. https://doi.org/10.1016/j.jhazmat.2011.01.060

[26] Shibata, E., Grabda, M. and Nakamura, T. (2006) Thermodynamic Consideration of the Bromination Reactions of Inorganic Compound-Considerations of Flame-Retardant Mechanisms and Degradation Recycling of Brominated Flame Retardant Plastics. Journal of the Japan Society of Waste Management Experts, 17, 361-371.

[27] Oleszek, S., Grabda, M., Shibata, E. and Nakamura, T. (2012) TG and TG-MS Methods for Studies of the Reaction between Metal Oxide and Brominated Flame Retardant in Various Atmospheres. Thermochimica Acta, 527, 13-21. https://doi.org/10.1016/j.tca.2011.09.014

[28] Grabda, M., Oleszek-Kudlak, S., Shibata, E. and Nakamura, T. (2009) Influence of Temperature and Heating Time on Bromination of Zinc Oxide during Thermal Treatment with Tetrabromobisphenol A. Environmental Science \& Technology, 43, 8936-8941. https://doi.org/10.1021/es901845m

[29] Grabda, M., Oleszek-Kudlak, S., Rzyman, M., Shibata, E. and Nakamura, T. (2009) Studies on Bromination and Evaporation of Zinc Oxide during Thermal Treatment with TBBPA. Environmental Science \& Technology, 43, 1205-1210. https://doi.org/10.1021/es802400y

[30] Oleszek, S., Grabda, M., Shibata, E. and Nakamura, T. (2013) Fate of Lead Oxide during Thermal Treatment with Tetrabromobisphenol A. Journal of Hazardous Materials, 261, 163-171. https://doi.org/10.1016/j.jhazmat.2013.07.028

[31] Oleszek, S., Grabda, M., Shibata, E. and Nakamura, T. (2013) Study of the Reactions between Tetrabromobisphenol $\mathrm{A}$ and $\mathrm{PbO}$ and $\mathrm{Fe}_{2} \mathrm{O}_{3}$ in Inert and Oxidizing Atmospheres by Various Thermal Methods. Thermochimica Acta, 566, 218-225. https://doi.org/10.1016/j.tca.2013.06.003

[32] Rzyman, M., Grabda, M., Oleszek-Kudlak, S., Shibata, E. and Nakamura, T. (2010) Studies on Bromination and Evaporation of Antimony Oxide during Thermal Treatment of Tetrabromobisphenol A (TBBPA). Journal of Analytical and Applied 
Pyrolysis, 88, 14-21. https://doi.org/10.1016/j.jaap.2010.02.004

[33] Grabda, M., Oleszek, S., Shibata, E. and Nakamura, T. (2014) Study on Simultaneous Recycling of EAF Dust and Plastic Waste Containing TBBPA. Journal of Hazardous Materials, 278, 25-33. https://doi.org/10.1016/j.jhazmat.2014.05.084 